\title{
Pseudomelanosis Duodeni
}
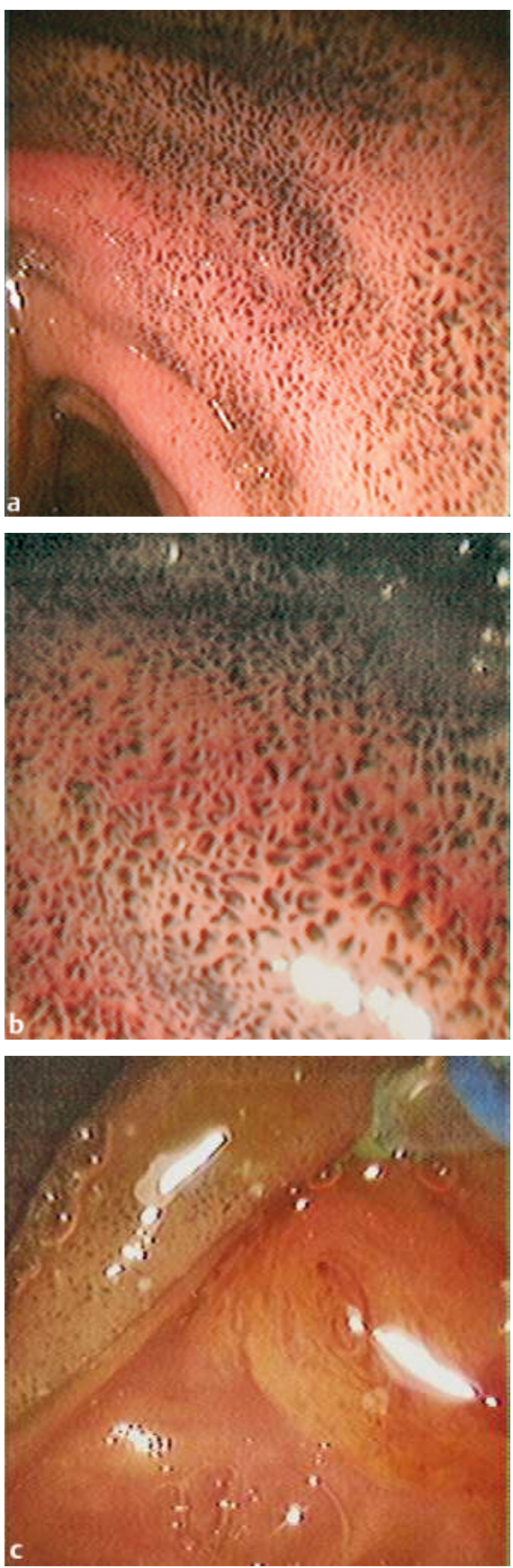

Figure 1 A 49-year-old man with chronic renal insufficiency, hypertension, and protein $\mathrm{S}$ deficiency presented with jaundice 3 days after undergoing laparoscopic cholecystectomy. This was investigated by endoscopic retrograde chlolangiopancreatography, when he was found to have abnormal pigmentation of the duodenal mucosal lining (a). Closer inspection of the mucosa revealed a speckled pattern of black lesions (b), which covered virtually all of the visible duodenum. The ampulla of Vater and neighboring mucosa were devoid of these black lesions, however, contrasting with the adjacent duodenal fold, which was pigmented (c).

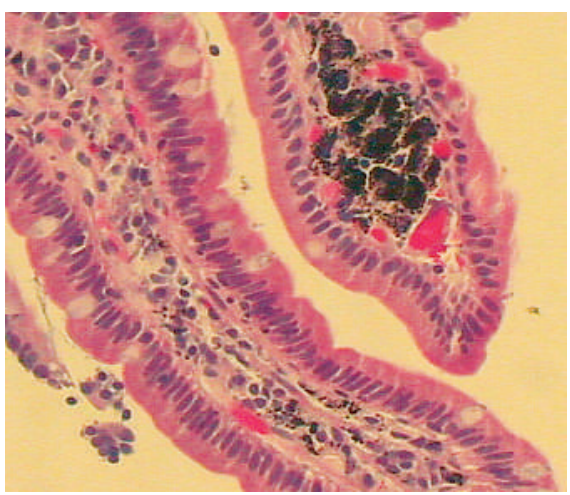

Figure 2 Histological examination of a duodenal biopsy showed aggregations of black granular pigment within the tips of the villi; the mucosa was otherwise unremarkable (hematoxylin $\&$ eosin, $\times 200$ ). The pigment was a ferrous sulfide compound and was located in the intracellular lysosomes. The sulfur group can be derived from antihypertensive medications. Interestingly, this patient had been treated with hydralazine, which contains a sulfur group.

\section{J. A. Cantu, D. G. Adler}

${ }^{1}$ The University of Texas Medical School at Houston, Houston, Texas, USA

2 Division of Gastroenterology and Hepatology, The University of Texas HoustonHealth Science Center, Houston, Texas, USA

\section{Corresponding Author}

\section{G. Adler, M.D.}

The University of Texas Medical School at Houston

6431 Fannin

MSB 4.234

Houston TX 77030

Texas

USA

Fax: $\quad+1-713-500-6699$

E-mail: Douglas.Adler@uth.tmc.edu 